\title{
Supplementary Information: Investigating the
}

\section{thermodynamic causes behind the anomalously large shifts in $\mathrm{pK}_{\mathrm{a}}$ values of benzoic acid modified graphite and glassy carbon surfaces}

Poobalasingam Abiman, ${ }^{\dagger}$ Alison Crossley, ${ }^{\ddagger}$ Gregory G. Wildgoose, ${ }^{\dagger}$ John H. Jones, ${ }^{\S}$ Richard, G. Compton ${ }^{1 \dagger}$

\section{XPS spectra of glassy carbon powder}

Supplementary figure 1 shows the XPS spectra (wide scans 0-1296 eV) of blank glassy carbon and BA-GC powder (offset for clarity) for comparison. Various impurities arising from the action of stirring the powder in borosilicate glassware can also be seen (unlabelled) in the spectra corresponding to silicon, fluorine and calcium.

Supplementary figure 1:

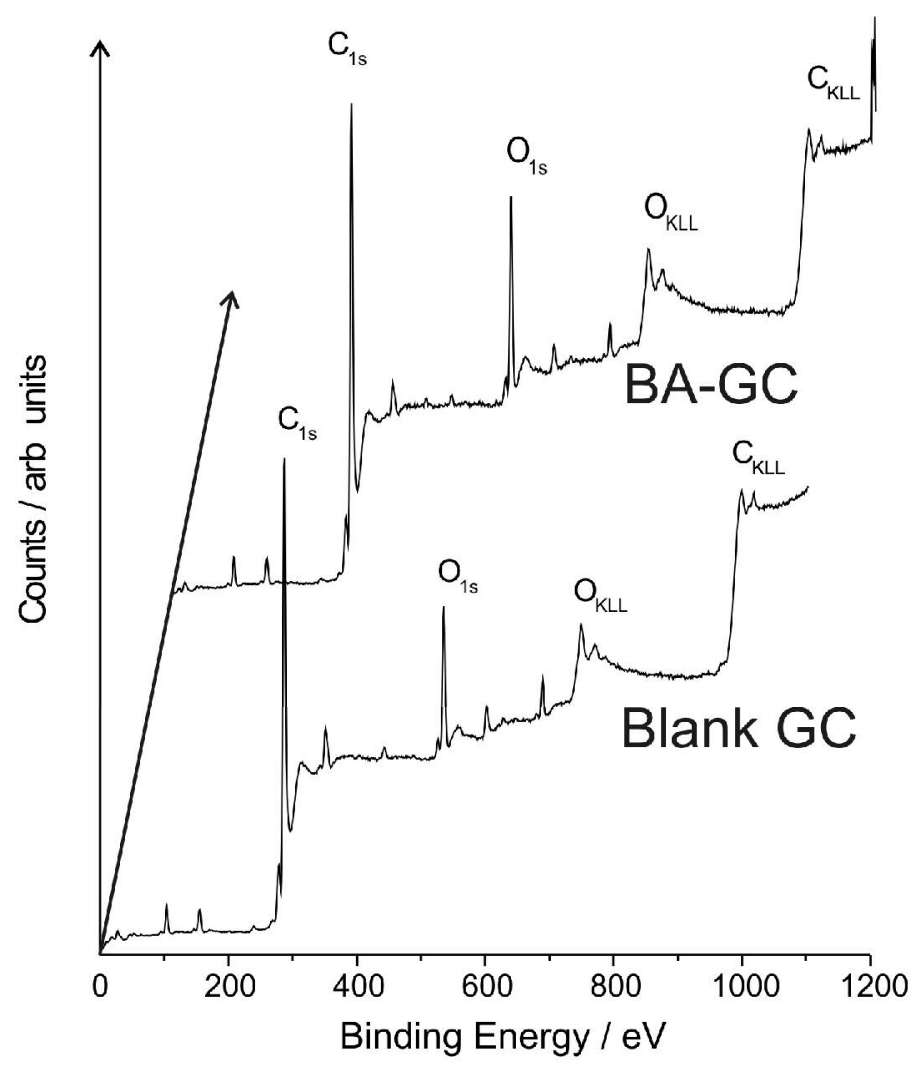

${ }^{1}$ Corresponding author: Email: richard.compton@chem.ox.ac.uk Tel: +44 (0)1865 275413 Fax: +44 (0)1865 275410 


\section{Potentiometric titration of benzoic acid in solution}

Supplementary Figure 2: a) A plot of $\mathrm{pH}$ versus volume of $\mathrm{NaOH}$ added at $25^{\circ} \mathrm{C}$ and b) the corresponding plot of $\mathrm{pH}$ versus $\log \left\{\left[\mathrm{PhCOO}^{-}\right] /\right.$ $[\mathrm{PhCOOH}]\}$ at $25^{\circ} \mathrm{C}$ for $0.01 \mathrm{M}$ benzoic acid in solution.
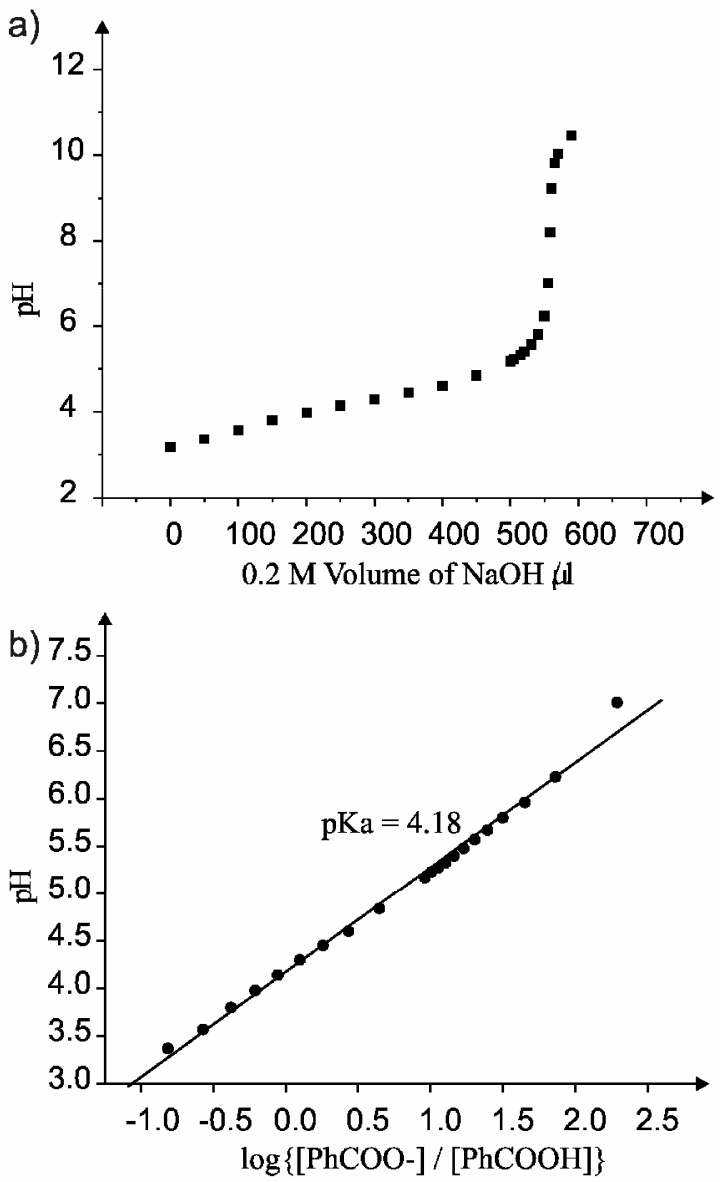
3. Potentiometric titration of BA-GC powder at $25^{\circ} \mathrm{C}$.

Supplementary Figure 3: a) A plot of $\mathrm{pH}$ versus volume of $\mathrm{NaOH}$ added at $25^{\circ} \mathrm{C}$ and b) the corresponding plot of $\mathrm{pH}$ versus $\log \left\{\left[\mathrm{PhCOO}^{-}\right]\right.$/ $[\mathrm{PhCOOH}]\}$ at $25^{\circ} \mathrm{C}$ for BA_GC powder.
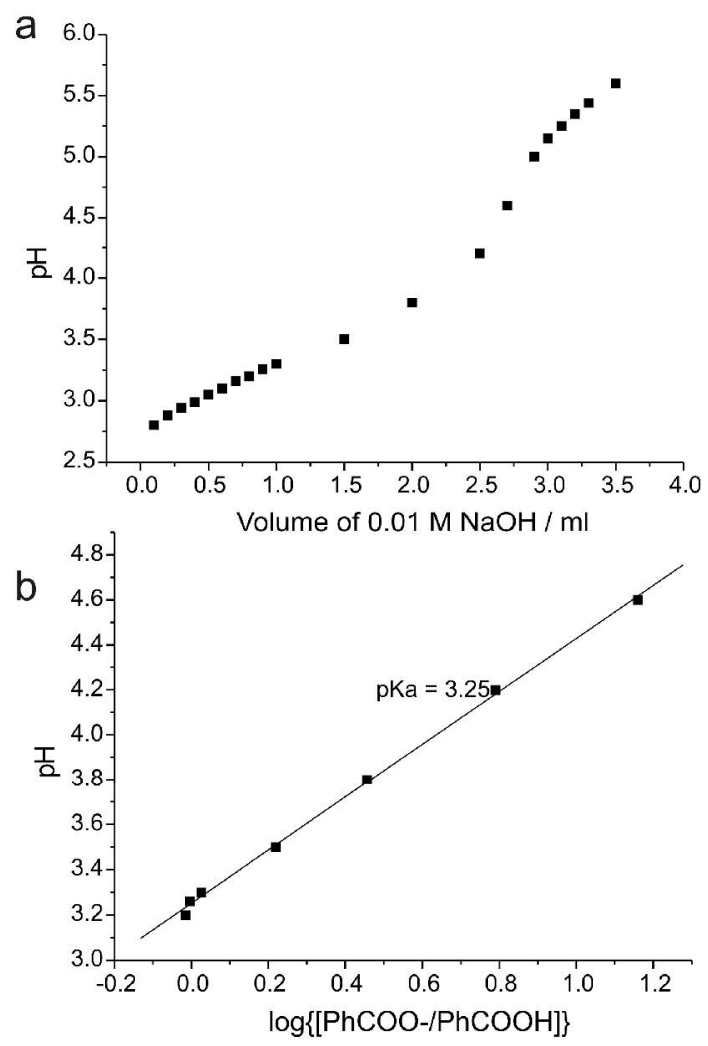

\section{Potentiometric titration of blank graphite}

Supplementary figure 4: $\quad$ potentiometric titration of blank graphite at $25^{\circ} \mathrm{C}$.

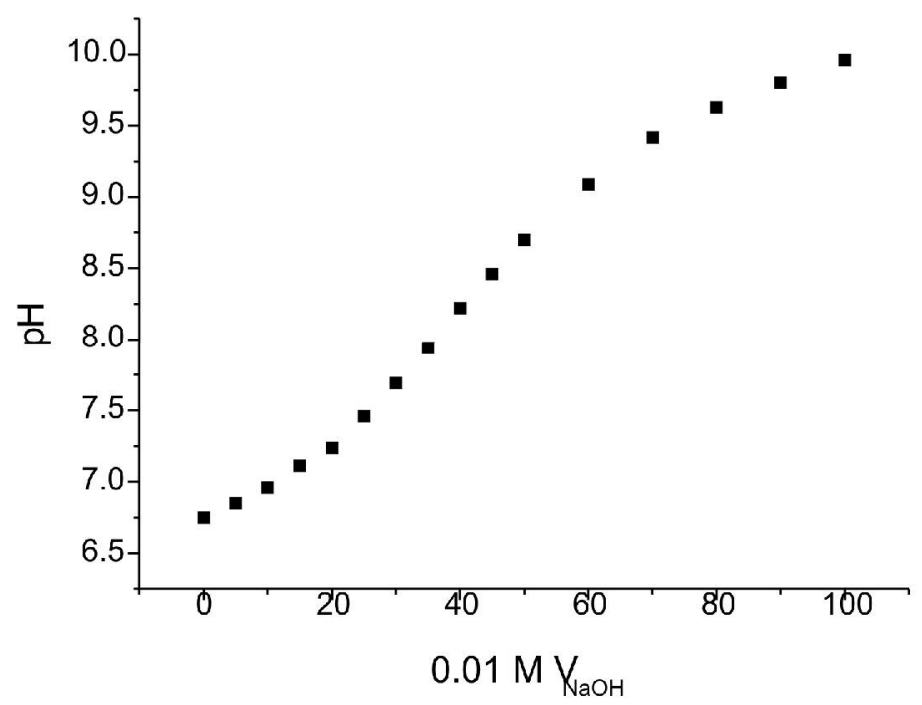

